\title{
Conceptualizing Contractual Interpretation
}

\author{
Alan Schwartz and Joel Watson
}

\begin{abstract}
Many litigated written contracts require interpretation, but few formal treatments of the interpretive process exist. This paper analyzes welfare-maximizing interpretive rules. It shows that (1) accurate interpretations maximize expected gains by rewarding parties only for compliant performances; (2) an optimal interpretive rule trades off these gains against the costs of writing contracts, investing in the deal, and trials; (3) an efficient interpretive process sometimes requires an adjudicator to decide on the basis of the writing and the tendered performance, without a trial; (4) courts maximize accuracy in interpretation rather than welfare, which yields too many trials, prevents some efficient contracting relationships from forming, and distorts contract writing; (5) party preferences regarding interpretation often are closer to first best than judicial preferences, so legal interpretive rules should be defaults; and (6) arbitration is more attractive to parties when the interpretive task requires inferring intent from a tendered performance rather than from a writing.
\end{abstract}

\section{INTRODUCTION}

Contract interpretation has been an important subject in the law-school world for decades. There have been few law and economics analyses and very few formal economic treatments, however. ${ }^{1}$ This paper does

ALAN SCHWARTZ is Sterling Professor of Law, Yale Law School and School of Management. JOEL WATson is Professor of Economics, University of California, San Diego, and Fellow, Center for Advanced Study in the Behavioral Sciences at Stanford University. We are grateful for Al Klevorick's extensive comments and for helpful audience participation at workshops at the Columbia Law School, Duke University School of Law, the University of Southern California Gould School of Law, the University of Toronto Faculty of Law, the Vermont Business School, and the National Bureau of Economic Research Summer Institute. We thank the Southern California Innovation Project for financial support.

1. The law and economics literature is summarized in Schwartz and Scott $(2010,2003)$ and discussed briefly below. A recent survey of the economics literature, Zhao (2010), discusses only two papers extensively.

[Journal of Legal Studies, vol. 42 (January 2013)]

(C) 2013 by The University of Chicago. All rights reserved. 0047-2530/2013/4201-0001\$10.00 
three things. First, it creates a model to show how contract interpretation works when an ideal enforcer does it. Second, it characterizes how the optimal interpretive rule trades off the costs and benefits of different sources of information, including the contract itself. This analysis serves as a premise for understanding parties' and decision makers' actual interpretive practices and for making policy suggestions as to how to improve those practices. Third, the paper compares the ideal enforcer to real courts, which we characterize as driven by an accuracy objective.

Our ideal enforcer is ideal in two senses. (1) Motivation: the enforcer's goal is to maximize welfare, which is the expected value of commercial transactions over the set of contractual relationships. (2) Expertise: the enforcer can make the cost/benefit calculations that this maximization exercise requires. In the model, a population of matched sellers and buyers choose their contracts, and then the sellers make private sunk-cost investments that stochastically increase the buyers' values for a product or a service. Hence, our ideal enforcer interprets contracts to induce sellers to invest efficiently.

The interpretive process requires two tasks: creating an interpretive rule and adjudicating interpretive disputes. ${ }^{2}$ An interpretive rule can be effective at motivating the seller to invest only if it induces the following accuracy condition to hold with high probability: the seller is paid if she renders a compliant performance and is not paid otherwise. The enforcer, we assume, observes the seller's performance. The interpretive issue for him thus is to decide whether the parties wanted the seller to tender exactly the observed performance.

The parties' goal is to maximize surplus; thus, they want to maximize the likelihood that the accuracy condition is satisfied. To do this requires the parties to make trade-offs among three sets of costs: (1) the cost of writing the contract, which conveys information about their intent, (2) the cost of investing in performance, which $(a)$ increases its value to the buyer and $(b)$ increases the likelihood that the seller will be found to comply, ${ }^{3}$ and (3) the cost of a possible trial, which also reveals intent. Unconstrained parties will make these trade-offs in privately, but not

2. Our enforcer can be thought of as a court. We use the term "enforcer" because we later ask whether parties would prefer an arbitrator or a court to adjudicate disputes. The enforcer can develop an interpretive rule through a series of decisions, as courts do, or the legislature could create the rule, as the Uniform Commercial Code does. In either case, rule creation comes first, so the rule may influence parties' contractual choices.

3. An actual performance is evidence of the intended performance. 
necessarily socially, optimal ways. An efficient interpretive rule induces welfare-maximizing trade-offs on these three margins.

To make this view of the interpretive process a little more transparent, we begin with an example. In the example, and in the model below, each contracting relationship is a particular type. The concept of type captures an intention: the performance that the contracting relationship intended to trade. A type $t_{i}$ relationship intends to trade a different thingdifferent goods or services-than a type $t_{j}$ relationship does. We assume that the seller must expend effort to ensure that the performance is compliant (the good or service is the intended one).

For illustrative purposes, let there be three party types, each of which intends to trade a grade of raw cotton that the buyer will make into cloth. There are seven cotton grades, ranging from grade 1 (Egyptian superfine) to grade 7 (Bulgarian). A type $t_{1}$ relationship intends to trade grade 1 cotton; the buyer in this relationship produces high-quality fabric for clothes sold in boutique stores. A type $t_{2}$ relationship intends to trade either grade 2 or grade 3 cotton; here the buyer produces fabric for moderately priced clothing, and either of these grades will do. A type $t_{3}$ relationship intends to trade grade 7 cotton: this buyer is making fabric for work clothes.

The enforcer observes the grade of cotton that the seller tenders. ${ }^{4}$ Assume first that the enforcer can recover the relationship type, and let the tendered grade be 4 . The enforcer would then find that the seller breached, since no type intended to trade grade 4 cotton. Next assume that the seller tendered grade 2 cotton. The enforcer would find that the seller's performance was compliant only if the relationship was determined to be type $t_{2}$.

Suppose next that the enforcer cannot recover type perfectly; he makes a determination of the type, which is likely to be accurate but with some probability is inaccurate. He then can make an interpretive error. For example, the enforcer could observe a tender of grade 2 cotton and believe that the relationship is type $t_{2}$, when in fact the type is $t_{1}$. Because the performance appears to match the type, the enforcer would then mistakenly order the buyer to pay. If such an outcome would occur with significant probability, then the seller's incentive to invest in effort would diminish.

In the common view, there is one interpretive task: to assign meaning to a contract's words when there is an interpretive dispute. This example

4. In the example, and in the model, the seller's physical performance is verifiable. 
is meant to suggest that the common view is not so much incorrect as too narrow. The adjudicative task is to identify contracting relationship types, and the parties' contract constitutes only one category of relevant evidence. There are three more. The performance the seller tendered is probative, more or less, of the performance the parties intended the seller to tender. The litigation documents-the complaint and answer, the exhibits-provide narratives from which type information may be extracted. Finally, trial evidence (testimony, documents), when permitted, also is probative of party type to some degree. In the model below, evidence in the four evidentiary categories are signals of party type. The enforcer's adjudicative task is to infer the litigation parties' type from these signals and then order the buyer to pay only if he believes that the seller's performance is compliant. A compliant performance, in turn, is the performance that is consistent with the parties' type, as the enforcer finds it.

An innovation of this paper is to analyze the rule-creation process and to show how an interpretive rule influences the parties' earlier choices. The rule's goal is to induce parties optimally to identify their types. A feature of the cotton example is that cotton has a wide variety of uses. Consider a different case. Let a particular rare-earth metal have only two industrial applications: in jet engines and in catalytic converters. In this case, the seller's performance-the type of rare-earth metal tendered-is highly probative of the parties' type. Tendering anything other than the particular rare-earth metal would be a breach for either the engine maker or the converter maker; tendering that rare-earth metal would be a compliant performance for both. An optimal interpretive rule would induce types that intend to trade the rare-earth metal at issue to write short contracts: a contract can describe either intended use concisely. In contrast, the relationship between a physical performance and a party type is less direct for cotton traders or, for example, oil traders (who deal with many types of oil with different uses). Hence, the optimal rule would induce cotton and oil traders either to write longer contracts or to rely on trial evidence, depending on whether it is more efficient to convey type in the writing or at a trial.

To summarize, the interpretive process includes, but is not constituted by, the job of attributing meaning to a contract's words. Rather, the process's task ex post is to recover a contracting relationship's type from the contract and other signals, and the task ex ante is to induce parties to take optimal actions both to create value and to facilitate accurate type identification. 
We use this understanding of the interpretive process to analyze some significant interpretive practices. As examples, there is a strong, though not complete, congruence between the ideal enforcer's goal and the parties' goals: the ideal enforcer and the parties both prefer to satisfy the accuracy condition efficiently. This congruence implies that parties seldom would want to tell an enforcer how to interpret their contract and how to utilize evidence. If actual parties often attempt to tell actual enforcers what to do, then real-world interpretation may deviate in material ways from the ideal. As a second example, enforcement institutions differ in the nature of the expertise they bring to bear. We analyze the nature of interpretive expertise to better understand how parties choose enforcement institutions.

We also want to provide a basis for making interpretive policy. To illustrate, let courts and parties actually differ regarding how much and what types of evidence courts should consider when making interpretations. An analysis of ideal interpretation may illuminate whose preferences should prevail. We generate the following results.

Inefficiency with the Ideal Enforcer. The accuracy condition cannot be perfectly satisfied: the costs of reducing uncertainty regarding the parties' intentions to zero exceed the incentive gains. Because efficiency requires absolutely correct interpretations, even an ideal enforcer cannot induce first-best investment incentives. The effect of residual uncertainty cannot be eliminated by punishing probabilistically noncompliant performances, if penalties are not permitted as aids to contract enforcement.

Optimal Contracting. As suggested above, an optimal interpretive rule induces parties to choose efficient contracts. If, say, a particular set of contracting relationships can best indicate their intentions by writing extensive contracts, the rule will induce them to write these contracts rather than simple contracts and a reliance on trials to reveal intent. It follows that, under some conditions, the enforcer optimally restricts trial evidence. In addition, an optimal interpretive rule correctly induces some potential relationships not to form. The cost of conveying intent, for them, would exceed the investment efficiency gain.

Forms of Expertise. Expertise in interpretation comes in three forms: expertise in extracting meaning from words, expertise in inferring party intentions by applying industry knowledge to evaluate a seller's performance, and expertise in evaluating trial evidence. ${ }^{5}$

5. Enforcers see similar evidence before and at trials, but evidence is evaluated differently at these litigation stages. For example, evidence at a court trial is presented through a 
Relation between Parameters. Institutional changes that lower contract-writing costs and changes that increase expertise in evaluating a tendered performance are complements; in contrast, changes that lower contract-writing costs and trial costs are substitutes. Regarding complements, a more extensive contract description better permits an enforcer to match the actual performance to the intended performance. Regarding substitutes, an extensive trial can make up for a sketchy contract. Illumination regarding the relationships among these variables of interest may facilitate legislative or administrative interventions to improve the efficiency of the interpretive process. ${ }^{6}$

Accuracy and Bias. When the enforcer maximizes accuracy in interpretation rather than welfare over the population of contractual relationships, welfare is lower; parties' contracting choices are biased, often unexpectedly in the direction of writing more complicated contracts; and some contracting relationships inefficiently fail to form.

Real Courts. Many courts do attempt to maximize accuracy (see Posner 2004), and actual parties commonly send interpretive instructions to them. ${ }^{7}$ These instructions almost invariably attempt to reduce the probability and cost of trials. ${ }^{8}$ Party instructions, if followed, thus would make courts function more as the ideal enforcer functions; hence, courts should obey them. Many courts today do not.

We conclude this Introduction with two remarks and a brief description of the literature. Recall that, in the common view, the interpretive task is to minimize the distance between the intention the interpreted words support and the parties' true intent. In our model, we invert this process. The enforcer treats the words as one of several signals that together support his inference of intent, an inference that is summarized in the enforcer's identification of the parties' probable type. Further, in the usual view, interpreters are not tasked with considering the cost of interpretive accuracy. In contrast, the enforcer, in his rule-making mode, induces parties, when pursuing their goal of identifying type to a latter adjudicator, to take optimally into account the costs of adjudication, contract writing, and party investment. We take a different view of the

prism of evidentiary rules that it takes an expert adjudicator to apply. Thus, a court may be better than an arbitrator at evaluating trial evidence but less good at just looking at a performance and inferring correctly whether the performance was intended.

6. See remark 6 for examples.

7. Instructions are included in the parties' contract.

8. For example, an instruction may direct the court not to consider oral statements the parties made to each other during a negotiation. Claims regarding these statements often are contested, so making statement evidence admissible increases the likelihood of a trial. 
interpretive process because we assume that the interpretive goal is to maximize welfare over a relevant set of contractual relationships. An interpretive rule realizes that goal, in our analysis, when it functions not so much to facilitate the finding of meaning as to maximize the costjustified probability that sellers are rewarded only for performances that are consistent with type.

Second, the subject of interpretation is important. Contract theory models exclude interpretive issues by assumption. In these models, the parties either describe the subject of trade perfectly or do not describe it at all. Perfect descriptions need not be interpreted, and null descriptions cannot be interpreted. In the usual case, however, the court can observe the performance the seller tendered, and the parties' contract describes the subject of sale imperfectly. In these contexts, the court is not asked to decide whether a party verified a payoff-relevant variable. The court instead must find what the parties intended that variable to be, which is an interpretive question. Judge Richard Posner thus estimated that 80 percent of the contract cases that come before the Seventh Circuit involve interpretive issues. ${ }^{9}$

Regarding the literature, our paper utilizes the same foundation as Shavell's (2006) model, whereby there is a population of contractual relationships with different types, contracting is costly, and contract selection partitions the space of relationship types and thus provides coarse information about type to the interpreter. ${ }^{10}$ We are also similarly focused on optimal interpretation to maximize social welfare. However, there are major differences between Shavell (2006) and this paper. First, there is no investment in Shavell's model, so the interpreter there is concerned only with ex post efficiency. In contrast, we analyze how the choice of interpretive practices can induce efficient investment, in which there are trade-offs between costs realized at different stages of productive relationships. Second, Shavell assumes that all terms have an exogenously defined literal meaning, and his results focus on demonstrating that it is sometimes optimal for the enforcer to depart from literal interpretation. ${ }^{11}$ We argue, in contrast, that context commonly is

9. For his views regarding interpretation, see Posner (2004).

10. The second feature follows the prior work on costly contracting and limits on describability (Dye 1985; Anderlini and Felli 1999; Battigalli and Maggi 2002; Schwartz and Watson 2004).

11. Shavell's (2006) interpreter generally follows, though he sometimes overrides, specific terms and fills gaps in contracts with efficient terms. Maggi and Staiger (2011), in the context of international trade agreements, also assume that aspects of the enforcement regime are exogenously fixed. 
indispensable to interpretation when the interpreter's task is to induce efficient party behavior, and we determine the optimal interpretive rule absent exogenous constraints on the meaning of contract terms. Doing this allows us to explore the implications of court bias toward accuracy. It also allows us to provide results on trade-offs in various dimensions of evidence and expertise and on the optimal use of multiple enforcers. ${ }^{12}$

Listokin (2010) considers a problem related to ours. He shows how a court that wants to maximize accuracy in interpretation would use Bayesian analysis to interpret contract terms. The enforcer in our model also does Bayesian updating, but our model differs in at least three significant respects from Listokin's. First, our enforcer maximizes welfare, not accuracy. Second, our enforcer interprets contracts in the service of inducing investment; there is no investment in Listokin's model. Third, a court cannot be a good Bayesian unless it has an informed prior. Listokin assumes that courts have such priors. In our model, the informativeness of the enforcer's prior is a facet of his expertise. This permits us to model the parties' choice of an enforcer.

Finally, Kvaloy and Olsen (2009) analyze a model with investment in which parties can affect the verifiability of payoff-relevant variables by the contracts they write and the investments themselves. This paper is illuminating regarding contract choice, but it assumes that values are deterministic and, importantly, that litigation is costless. The last assumption is limiting because the common question for parties, and for our enforcer, is when is it efficient to reveal their initial intentions in a costly contract or in a costly trial or in some combination of these?

Section 2 sets out the model, which Section 3 solves. Section 4 is a conclusion. Some details of our analysis and proofs of our technical results are in Appendix A. Appendix B contains an extension of our analysis to the case of multiple enforcers, which we hope might usefully serve as a bridge between our theory and future empirical work. A pilot study may be found in the working paper version of this paper ( $S$ chwartz and Watson 2012).

\section{THE MODEL}

\subsection{A Technical Description}

There is a population of contractual relationships, each one a match between a buyer and a seller. Relationships are differentiated by a type

12. This issue is addressed in Appendix B. 
parameter $t$, which summarizes what the parties agree to trade and other payoff-relevant aspects of their relationship. The type space is drawn from a uniform distribution over the interval $[0,1] .{ }^{13}$ Disputes between the parties are adjudicated by an external enforcer who has three tasks: to develop an interpretive rule that governs how a relationship's type can be identified, to make a finding as to type in contested cases, and to compel monetary transfers between the parties (or not) as a function of the type decision. The enforcer's goal, in performing these tasks, is to maximize aggregate welfare over the population of contractual relationships. Interaction among the three agents in the model-buyer, seller, and enforcer-is as follows.

Date 1. The enforcer creates and publishes his interpretive rule.

Date 2. A buyer and seller agree to trade a product or a service. They then choose a controlling contract that contains a price, normalized to one, and a set of nonprice terms that, more or less, describe the subject of sale and other governing conditions. The nonprice terms are indexed by the integer $k$, where $k \in \mathbf{P}=\{0,1,2,3, \ldots\}$. The parties jointly pay the contracting cost $y_{k}>0$. Contracts are ordered so that $y_{k}$ is increasing in $k .{ }^{14}$ We assume that $y_{0}=0$ and for every $\kappa$ there is a $k$ such that $y_{k}>\kappa$. This assumption implies that contract costs may exceed possible trading gains for some potential contractual relationships.

Date 3. The seller chooses an investment level $q \in[0,1]$ at cost $c(q)$. The probability that the seller's performance is compliant-that is, it is the performance the buyer in a type $t$ relationship would want-is increasing in $q$. The investment level is private information, so parties cannot contract on $q$.

Date 4. The seller tenders a performance, which the buyer observes. With probability $q$, the seller's performance is compliant. With complementary probability $1-q$, the performance is noncompliant. The buyer realizes a benefit of one if the performance is compliant and zero if not.

Date 5. Either the buyer accepts the performance and pays the contract price, in which case the game ends, or the buyer rejects. A dispute follows rejection. $^{15}$

13. This is a continuum, so there is an infinite number of possible types.

14. Note that $k=0$ represents no contract: a potential buyer and seller reject a relationship.

15. The seller can sue the buyer for the price, or the buyer can sue the seller for damages. 
Date 6. The enforcer observes information that the litigation yields, except evidence that only a trial would reveal. Pretrial evidence includes the contract $k$ and a signal, denoted $x$, that the seller's physical performance sends. ${ }^{16}$ A compliant performance commonly is probative regarding the parties' type $t$-that is, what they agreed to trade. Consequently, we suppose that if the performance is compliant, then $x$ equals the relationship's type $t$ with probability $s>0$, and with complementary probability $x$ is drawn from the uniform distribution over the set of types. If the performance is noncompliant, $x$ is drawn from the uniform distribution for sure. ${ }^{17}$ The three agents in the model observe the contract and the performance signal $x$.

Date 7. The enforcer forms a belief about the parties' type $t$ and whether performance was compliant on the basis of the litigation documents, the contract, and the performance signal $x$. He then orders the buyer to pay or not. If the enforcer orders payment, then he also decides whether to permit trial evidence if the buyer offers it. ${ }^{18}$

Date 8. The buyer decides whether to submit trial evidence, at cost $\gamma \geq 0$, if the enforcer permits it. ${ }^{19}$ We assume for convenience that trial evidence perfectly reveals the type $t$. The enforcer, at this stage, then makes a final determination of whether to order the buyer to pay, either on the basis of all evidence or with pretrial evidence only. ${ }^{20}$

16. The common distinction in the legal world is between intrinsic and extrinsic evidence. Intrinsic evidence corresponds to what we mean by pretrial evidence: the parties' litigation narratives, the contract, and the performance, all of them evaluated with whatever expertise the enforcer possesses. Extrinsic evidence is what we mean by trial evidence: the parties' practice under prior contracts, their practice under the existing contract, evidence of precontractual negotiations, precontractual memoranda and preliminary contract drafts, and industry custom. Some extrinsic evidence may be revealed in discovery proceedings, but evidence in these categories is usually contested and so settled at trial. For example, the buyer may claim that the seller's performance was noncompliant, as measured by the custom in the parties' industry. The seller may deny the existence of a custom or claim that she satisfied it. We refer to extrinsic evidence as trial evidence because its weight and materiality usually is settled at trial. For a further discussion, see Schwartz and Scott (2003) and authorities cited therein.

17. The signal is unilluminating in either event because the type space is uniform.

18. The enforcer's interpretive rule governs when trial evidence is permitted.

19. Trial evidence provision is inefficient ex post because at stake then is only whether the buyer should make a transfer. As we show below, an interpretive rule that creates efficient investment incentives makes the correct decision as to whether to permit evidence.

20. We note two other features of the model. First, sellers sometimes breach by not tendering a performance at all. In such cases, the enforcer proceeds as we have noted but without the performance signal. Second, the enforcer does not update his type finding by considering a buyer's refusal to accept delivery because the refusal is too noisy a signal. A buyer 
Welfare is maximized when the seller chooses $q$ to solve $\max _{q} q-$ $c(q)$. The cost function $c$ is twice continuously differentiable, with the standard properties $c^{\prime}>0, c^{\prime \prime}>0, c^{\prime \prime \prime}>0$, and $\lim _{q \rightarrow 1} c(q)=\infty$. Let $q^{*}$ denote the solution to this maximization problem, so $c^{\prime}\left(q^{*}\right)=1$.

\subsection{Explanation and Additional Notation}

It is helpful, in understanding how interpretation functions in the model, to clarify further how the enforcer identifies a relationship's type. In our cotton example, we list four categories of evidence. An enforcer may observe some of these categories at approximately the same time-the contract may be attached to the seller's complaint-but it is convenient to suppose that the enforcer observes these categories in the order set out here.

In the cotton example, the enforcer learns from the litigation documents that he should search only over cotton-trading types. Formally, the parties' type $t$ is drawn from an interval of the type space that includes possible cotton traders. An expert enforcer may narrow this interval further. Thus, the narrative may permit him to exclude types that trade cotton blankets. The enforcer next observes the contract. These sometimes detail the parties' circumstances and usually describe, more or less precisely, what the seller is to do.

The litigation narrative and the contract thus provide information about (that is, are signals of) the parties' type. Evidence in these evidentiary categories permits the enforcer to reduce the type space to a subinterval of $[0,1]$ in which, he comes to believe, the litigation parties' type likely lies. We let $S$ denote the subinterval that these two evidentiary categories permit the enforcer to identify. To be clear, the enforcer continues to believe that relationship types are uniformly distributed but now only over the subinterval $S$.

The types that constitute $S$ may use contracts that appear similar to the enforcer, however. ${ }^{21}$ As a consequence, the mass of types in $S$, denoted $\sigma$, is relevant to interpretation. If $\sigma$ is large-a substantial number of relationships are in $S$ but appear similar on the basis of the litigation story and the contract-much residual uncertainty as to the litigation parties' type may exist. Such uncertainty is a real possibility when, as

can reject for in-model considerations-he believes the goods do not conform-or out-ofmodel considerations - he has had a bad realization and no longer wants the goods.

21. This is an implication of positive contracting costs, which often preclude perfect individuation. 
in our formal model, there is a continuum of types (our cotton-trading example assumed a discrete, finite set of types for simplicity).

The enforcer next observes $x$-the seller's physical performance. Suppose initially that $x$ is in the previously formed $S$ subinterval. Recalling that a compliant performance is probative of what a compliant performance is supposed to be, the enforcer thus puts positive probability mass on the type being equal to $x$ exactly. To be precise, he believes

$$
\begin{aligned}
\operatorname{Pr}[x=t \mid x \in S] & =\operatorname{Pr}[x \in S \mid x=t] \operatorname{Pr}[x=t] / \operatorname{Pr}[x \in S] \\
& =q s /[q s+q(1-s) \sigma+(1-q) \sigma] \\
& =q s / \sigma(1-q s) .
\end{aligned}
$$

The enforcer believes with complementary probability that the parties' type is some other point in $S$, but he cannot put strictly positive probability on any such point because the $S$ interval is a continuum. ${ }^{22}$

Suppose next that $x$ is not in $S$. Then the enforcer's posterior probability about $t$ will not move: a noncompliant performance cannot indicate what a compliant performance was supposed to be. More precisely, when $x$ is outside of $S$, the enforcer continues to believe that the parties' type is in $S$, but because the distribution in $S$ is uniform, he does not put positive probability on any particular type in this interval.

The enforcer thus conditions his judgment regarding whether or not the buyer is to pay on the set $S$ and the signal $x$ (which yields a posterior belief about the relationship's type). As a consequence, the enforcer can create a wedge between the seller's expected payoff for a compliant performance and her payoff for a noncompliant performance. The existence of this wedge, in turn, affects the seller's choice of an investment level. We show below that the enforcer optimally orders the buyer to pay without trial evidence only when $x$ is in $S$. This interpretive practice

22. The variable $q$ appears in the enforcer's Bayesian calculation although $q$ is private information. The enforcer infers $q$ from prior information, and this inference turns out to be correct in equilibrium. To anticipate later results, the Bayes's rule calculation indicates that the enforcer's ability to identify type is increasing in $s$. Intuitively, the more precise the performance, the less likely the enforcer is to draw the wrong inference. For example, if the contract says "Rembrandt" and the seller delivers a Rembrandt, the enforcer may continue to be uncertain as to whether the seller complied. His ability to identify type is decreasing in $\sigma$, the number of types in $S$ who appear similar on the basis of their contracts and narratives. There are a number of Rembrandts, which materially differ, so the signal $s$ that performance sends here may not get the enforcer very far along. In contrast, the enforcer would likely believe a seller's performance is compliant if the contract said "Klimt" and the seller delivered a Klimt: this artist is traded infrequently, so tender of a Klimt would send a strong signal that a Klimt was intended. 
functions imperfectly, however, because the three signals on which the enforcer decides may not identify the true $t$ with certainty. The enforcer is mistaken if $x$ is in $S$ but $t$ does not equal $x$ : that is, the signal misleadingly points to a particular type and, thus, to a compliant performance. The enforcer would then incorrectly order the buyer to pay, and this creates an incentive for the buyer to introduce trial evidence.

The parties thus must make three trade-offs: between the cost of writing a more extensive contract and the more accurate adjudications a more extensive contract permits; between the seller's investment cost and the expected benefits of investment, as just described; and between the cost of introducing trial evidence and the accuracy gain. We stress here the relationship between the enforcer's interpretive rule and the parties' choice of a contract. The rule precedes this choice. Therefore, although parties know that they can make the contractual signal more or less illuminating depending on how much, or what, they write, the contract must fit into the world of the rule. As an example, we later show that contract length-a proxy for informativeness-and the enforcer's expertise in evaluating the performance signal are complements. If the enforcer has this particular expertise, the interpretive rule optimally induces parties to write longer contracts. In contrast, contract length and trial evidence are substitutes. If the enforcer's expertise primarily consists in evaluating trial evidence, the interpretive rule optimally induces parties to write shorter contracts and, therefore, to rely more on trials to reveal type. The parties would waste resources if they wrote a longer contract in this context; if a dispute arises, there likely would be a trial anyway. The interpretive rule thus channels the parties' contractwriting choices. If the rule is optimal, the channeled contracts efficiently convey type.

Finally, although the formal model supposes that disputes are resolved at a trial, our results would also hold if there can be a settlement. We can interpret $\gamma$ as the buyer's costs of preparing and producing evidence at the pretrial stage. The buyer will have to engage in some manner of evidence production before settlement negotiation takes place. The outcome of settlement negotiation is influenced by the anticipated outcome of a trial, which itself is influenced by the contract, performance, and evidence. The basic logic of the model thus holds if settlement is permitted.

Here is a glossary of notation:

$$
t=\text { a contracting relationship's type; }
$$


$S=$ the interval on the type space in which the enforcer believes the parties' type falls after observing their litigation story and their contract;

$\sigma=$ the mass of types in an interval $S$ (that is, the length of this interval);

$q=$ the investment level the seller chooses and the probability that the seller tenders a compliant performance;

$c(q)=$ the seller's cost of choosing investment level $q$;

$y_{k}=$ the cost of writing contract $k$;

$x=$ the performance signal the enforcer infers from the seller's physical performance;

$s=$ the probability that the performance signal, $x$, equals $t$ conditional on a compliant performance; and

$\gamma=$ the buyer's cost of providing trial evidence.

\section{ANALYSIS AND RESULTS}

The enforcer maximizes welfare across the population of contractual relationships. Thus, he wants parties to respond optimally regarding contract choice to the interpretive rule he creates. As a consequence, interpretation presents a single-person decision problem-a planner's problem-that involves the simultaneous choice of interpretive rule and contract for each relationship type. The optimal interpretive rule-the solution-induces parties to sort themselves, through the contracts they choose, into subsets of the type space. To see the relevance of this process for interpretation, recall the cotton example in the Introduction. The enforcer can use the litigation documents to infer that the type space includes cloth traders but not blanket traders. When the enforcer observes a cloth-trader relationship that uses contract $k$, the contract may permit an updated inference that the parties' type is in a smaller subset: traders of cloth to be used for fine clothing (as opposed to, say, traders of cloth to be used for work outfits).

\subsection{When the Enforcer Should Require Payment}

The enforcer's substantive goal is to induce sellers to invest efficiently. This objective is best served by paying the seller if and only if performance is compliant. In this model, efficient investment (the first best) is achieved exactly if the seller expects to receive a value of one (the buyer's value) when she complies. Anticipating this price, the seller maximizes $q-c(q)$ and selects the optimal investment level $q^{*}$. 
An insight of the model is that even an optimal interpretive rule cannot induce parties to choose first-best investment levels. There are two reasons. First, the seller expects to receive less than a value of one in return for compliance because the enforcer cannot identify a compliant performance with certainty. Positive contracting costs may preclude perfect individuation (the contract cannot identify type exactly), and the performance signal $x$ correlates with type imperfectly. ${ }^{23}$ The seller's marginal benefit from investment falls as she becomes less certain of payment for compliance. Second, the investment margin cannot be scaled up because the price is capped at a value of one. We assume a cap because one is the buyer's value, and penalties (contractual recoveries above the gain a party would realize from performance) are not enforced in modern states. Also, as a practical matter, parties seldom can pay arbitrarily large transfers. ${ }^{24}$

Turning to conditions under which the enforcer should order the buyer to pay in this imperfect world, recall that the enforcer uses the litigation documents and the contract (which his rule may induce) to locate the parties in an interval $S$ of the type space. The enforcer then observes the seller's performance. The signal it sends can yield two outcomes: the signal $x$ is in $S$ or it is not in $S$. In relative terms, the event $x \in S$ (where the performance signal is consistent with what the enforcer has already inferred about type) is good news about compliance. In contrast, the event $x \notin S$ is bad news (suggesting noncompliance). An optimal interpretive rule thus maximizes the seller's marginal benefit from investment if it directs the enforcer to order the buyer to pay if $x \in S$ and to allow the buyer to exit if $x \notin S$.

The interpretive rule also may allow trial evidence. We assume that evidence sometimes is cost justified: $\gamma<1$. In the model, evidence is assumed to be perfectly revealing. Therefore, the buyer would produce evidence if and only if the performance signal satisfies $x \in S$ (so that payment would be ordered in the absence of evidence) but $x \neq t$. The enforcer thus reverses his payment decision when he sees evidence.

\subsection{When the Enforcer Should Admit Evidence}

The enforcer's rule should admit trial evidence when admission maximizes the value of relationships. We show here that admission is optimal

23. Recall from the model's description that when the seller tenders a compliant performance, $x=t$ with probability $s$, but $0<s<1$.

24. The assumption that transfers are bounded is not critical to the ideas we explore. One can construct other versions of the model without a transfer constraint and with features similar to those discussed here, but these are more complex to analyze. 
when evidence costs are low, the performance signal $x$ is relatively inaccurate (a compliant performance fails to indicate clearly which performance was intended), and/or a relatively large number of types use similar contracts.

To begin, when evidence is admissible the seller's expected payoff from investing $q$ is $q s-c(q)$. This is because the seller gets paid if and only if she complies (with probability $q$ ) and the performance signal confirms compliance (that is, $x=t$, which happens with probability $s$ conditional on compliance). Otherwise, the performance signal satisfies $x \neq t$, and either it is outside the set $S$ (so the enforcer knows $x \neq t$ ) or it is in $S$ but the buyer provides evidence to show that $x \neq t$. The seller's optimal investment level, $q^{\mathrm{E}}$, thus satisfies the first-order condition $s=c^{\prime}\left(q^{\mathrm{E}}\right)$, with E denoting the admission case.

When evidence is admissible, the expected joint value of a relationship the enforcer knows to be in the set $S$, gross of contracting costs, is

$$
v^{\mathrm{E}} \equiv q^{\mathrm{E}}-\gamma\left(1-s q^{\mathrm{E}}\right) \sigma-c\left(q^{\mathrm{E}}\right) .
$$

The first term on the right-hand side is the expected benefit of the seller's performance. ${ }^{25}$ The last term is the seller's effort cost. The second term is the expected cost of introducing trial evidence: evidence cost $\gamma$ times the probability that the buyer will want to introduce evidence. There are two contingencies in which the buyer will provide evidence. In the first contingency, performance is compliant (with probability $q^{\mathrm{E}}$ ), but the performance signal is unilluminating (with probability $1-s$ ), and by chance the signal falls in the interval $S$ (with probability $\sigma$ ). The probability of this contingency is thus $q^{\mathrm{E}}(1-s) \sigma$. In the second contingency, performance is noncompliant, and the signal falls in $S$. The second contingency occurs with probability $\left(1-q^{\mathrm{E}}\right) \sigma$. The sum probability of these contingencies is $\left(1-s q^{\mathrm{E}}\right) \sigma$.

Referring again to the seller's first-order condition, we see that because $s<1$ (that is, the performance signal is not perfectly accurate) the seller chooses a suboptimal investment level. ${ }^{26}$ As a consequence, the value of a relationship, $v^{\mathrm{E}}$, is increasing in $q^{\mathrm{E}}$.

Suppose next that the enforcer's rule disallows trial evidence. The seller's expected payoff from choosing $q$ is then

$$
q[s+(1-s) \sigma]+(1-q) \sigma-c(q) .
$$

25. The probability of compliance is $q$ when the seller invests $q$. The buyer realizes a value of one from a compliant performance. Hence, the expected gross value of the contract is $q$ times one, or $q^{\mathrm{E}}$, when the parties expect evidence to be admitted.

26. Recall that the optimal investment level is one. 
The first term characterizes the two cases in which the seller tenders a compliant performance (with probability $q$ ) and the enforcer orders payment: the performance signal is accurate $(x=t)$, and the performance signal is unilluminating (with probability $1-s$ ) but by chance the signal falls in the interval $S$. The second term is the probability that performance is noncompliant but the enforcer fails to recognize noncompliance because the performance signal also is in $S$. Evidence is disallowed here, so the enforcer again orders the buyer to pay. The first-order condition for effort when trial evidence is barred is $s(1-\sigma)=c^{\prime}(q)$. Let $q^{\mathrm{N}}$ denote the solution. The expected joint value of a relationship in the set $S$, gross of contracting costs, then is

$$
v^{\mathrm{N}} \equiv q^{\mathrm{N}}-c\left(q^{\mathrm{N}}\right)
$$

A comparison of the two first-order conditions is illuminating:

$$
\begin{gathered}
\text { evidence: } s=c^{\prime}\left(q^{\mathrm{E}}\right) ; \\
\text { no evidence: } s(1-\sigma)=c^{\prime}\left(q^{\mathrm{N}}\right) .
\end{gathered}
$$

These first-order conditions have three intuitive implications. First, the seller exerts less effort when evidence is excluded. ${ }^{27}$ Second, the seller exerts less effort as $s$ falls-that is, as the performance signal becomes less accurate. The less accurate the signal is, the less likely the seller is to be rewarded for a compliant performance, so the lower is her reward for investing. Third, the seller exerts less effort as $\sigma$ increases-as more types seem similar to the enforcer without trial evidence. Again, the seller is less likely to be rewarded when the enforcer is less able to distinguish among possible contracting types.

Our last step is to compare the aggregate value of relationship types, with and without evidence, for those in a given set $S$ who choose the same contract. Initially comparing $v^{\mathrm{E}}$ and $v^{\mathrm{N}}$, we find that $v^{\mathrm{E}}$ is reduced by the expected value of introducing evidence. In contrast, the seller works harder when she anticipates that evidence will be admitted. The enforcer's accuracy is increasing in the seller's effort. The enforcer's rule, thus, should trade off saving trial costs against the fall in effort incentives that less accuracy yields.

To see how the enforcer proceeds, it is convenient to write the value expressions as functions of $\sigma$, the length of the $S$ interval, and maximize

27. Because $\sigma>0$, the left-hand side in the evidence case is larger than the left-hand side in the no-evidence case, which implies that on the margin the seller chooses a higher investment level when she anticipates that evidence will later be admitted. 
over whether to allow evidence. Welfare gross of contracting costs as a function of $\sigma$ is

$$
w(\sigma) \equiv \sigma \max \left\{v^{\mathrm{E}}(\sigma), v^{\mathrm{N}}(\sigma)\right\} .
$$

There is a number $\underline{\sigma}>0$ such that welfare is increasing for $\sigma<\underline{\sigma}$ and is decreasing for $\sigma>\sigma$. This is because it is suboptimal for a large number of relationship types to choose the same contract; rather, some of these relationship types should not enter into a contract at all. ${ }^{28}$

Turning to the main issue, we note that it is optimal to disallow evidence when $\sigma$ is small and $s$ is high but to allow it as $\sigma$ grows or $s$ falls. We express this conclusion in lemma 1.

Lemma 1. As a function of $\sigma, v^{\mathrm{E}}$ is affine and decreasing, and $v^{\mathrm{N}}$ is strictly concave and decreasing. There is a number $\sigma^{\mathrm{E}} \in[0,1]$ such that $v^{\mathrm{E}}(\sigma)>v^{\mathrm{N}}(\sigma)$ for $\sigma>\sigma^{\mathrm{E}}$ and $v^{\mathrm{E}}(\sigma)<v^{\mathrm{N}}(\sigma)$ for $\sigma<\sigma^{\mathrm{E}}$. A necessary and sufficient condition for $\sigma^{\mathrm{E}}=0$ is $\gamma\left(1-s q^{\mathrm{E}}\right) c^{\prime \prime}\left(q^{\mathrm{E}}\right)<s(1-s)$, which holds in particular if $\gamma$ is close to zero. More generally, $\sigma^{\mathrm{E}}$ becomes smaller as $\gamma$ falls or if $s$ becomes moderately high.

The proof of lemma 1 and the proofs for the propositions that follow are in Appendix A.

The intuition for lemma 1 has been partly explained above: (1) trial evidence increases accuracy, which is good, so an optimal interpretive rule should admit more evidence as evidence production costs fall, (2) when the performance signal is very accurate- $s$ is high - the enforcer may not need a trial to determine type, and (3) when a large number of types use the same contract, the other pretrial signals of typelitigation narrative and performance-may be insufficient to determine type accurately. Then a trial may be helpful. We illustrate these conclusions in Figure 1. The realistic case has $\sigma^{\mathrm{E}}>0$ because $\gamma$ (trial cost) is positive. The right-hand graph in Figure 1 thus shows that the value of relationships without evidence exceeds the value with evidence when $\sigma$ is small. As $\sigma$ gets larger-more types seem similar to the enforcer on the basis of their contracts-trial evidence becomes helpful for distinguishing among contracting relationships.

\subsection{How the Interpretive Rule Optimally Partitions Types}

In Section 3.2, we derived the optimal interpretive rule for any set $S$ of types that choose the same contract. We next describe how the rule

28. Note that $q^{\mathrm{E}}(0)=q^{\mathrm{N}}(0)$, and so $v^{\mathrm{E}}(0)=v^{\mathrm{N}}(0)$; the latter is the slope of $w$ at $\sigma=0$. 


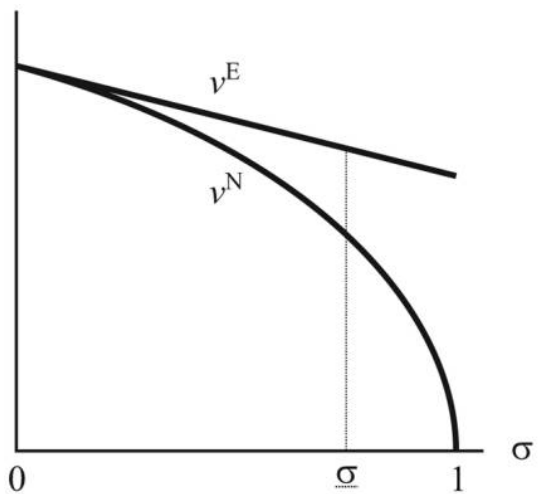

The case of $\sigma^{\mathrm{E}}=0$.

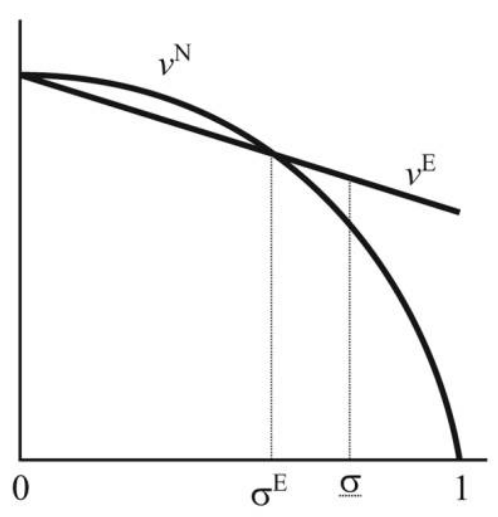

The case of $\sigma^{\mathrm{E}}>0$.

Figure 1. Values with and without evidence

partitions the type space into sets that choose distinct contracts. The optimal partition solves the following planner's problem.

Proposition 1. The optimal interpretive rule and the relationships' equilibrium behavior solve the problem of selecting an integer $K$ and numbers $\sigma_{0}, \sigma_{1}, \sigma_{2}, \ldots, \sigma_{K}$ to maximize $\sum_{k=1}^{K}\left[w\left(\sigma_{k}\right)-\sigma_{k} y_{k}\right]$, subject to $\sum_{k=0}^{K} \sigma_{k}=1$. For each $k=1,2, \ldots, K, \sigma_{k}$ is the size of the set of relationships that select contract $k$.

Remark 1. When parties create a contract, they know what the enforcer will later see-the context, the contract, the performance-and the interpretive rule he uses to identify their type. Hence, each relationship type prefers the contract meant for it. Some relationships also may not form. For example, potential parties may realize that, under the interpretive rule in place, the enforcer cannot identify a conforming performance without the aid of an extensive contractual description or a trial. The contracting or trial cost may exceed particular parties' gains from better effort incentives. An optimal interpretive rule induces parties to make these benefitcost calculations correctly.

Remark 2. For the parameterization that produced the right-hand graph of Figure 1, the welfare function $w$ is not concave: $\sigma^{\mathrm{E}}>0$. For some classes of contracting costs (for instance, $y_{k}=0$ up to some large 
$K$ and large $y_{k}$ for higher values of $k$ ), the optimal interpretive rule creates a partition with equally sized components, and the enforcer allows evidence. In general, however, the optimal interpretive rule may induce $\sigma_{k}>\sigma_{j}$-more relationships use contract $k$ than contract $j$-and it may allow evidence for party types that use $k$ but not for party types that use $j$. Another way to put this result is that if the enforcer allows evidence for a contract that $\sigma_{k}$ parties use, he will allow evidence for any contract that fewer parties use.

Remark 3. The enforcer's and the parties' goals are largely congruent. All must trade off contract writing, trial, and investment costs against the gains from greater interpretive accuracy, and all want these trade-offs made efficiently. The enforcer, however, maximizes over the set of contractual relationships, while individual relationships maximize individual gains. A conflict could arise if, say, parties in a particular relationship prefer not to have a trial, while the enforcer wants to face similar types with the prospect of a trial. The enforcer could have this preference if relationship types respond to the prospect by writing more informative contracts, and it is cheaper to induce the efficient effort level, in the context at hand, through contracts than it is through trials. A concrete implication of this conflict would have an ideal enforcer sometimes refusing to follow particular parties' interpretive instructions: for example, an instruction to bar all trial evidence.

\subsection{A Less Than Ideal Enforcer}

Actual enforcers may depart from the model's ideal enforcer in systematic ways. Courts are the principal example: many courts maximize accuracy in interpretation-the correct identification of type-rather than efficiency in investment. A reasonable model of such courts is that they choose interpretive rules to maximize $\sum_{k=1}^{K}\left[\sigma_{k} v^{\mathrm{E}}\left(\sigma_{k}\right)-\sigma_{k} y_{k}\right]$ rather than $\sum_{k=1}^{K}\left[w\left(\sigma_{k}\right)-\sigma_{k} y_{k}\right]$. Regarding these objective functions, we see that the enforcer's interpretive rule takes evidence costs into account and so does not maximize the unconstrained value of relationships. The judicial enforcer's rule always admits evidence; hence, he does maximize the unconstrained value of relationships.

The characterization results of proposition 1 continue to hold if we substitute the unconstrained maximum $\sigma v^{\mathrm{E}}(\sigma)$ for $w(\sigma)$ in the statement of the proposition. Doing this permits us to compare the optimal interpretive rule that an accuracy-driven enforcer creates with the optimal rule of the welfare-maximizing enforcer. The comparison yields a sur- 
prising result. Intuition apparently suggests that because the accuracydriven enforcer permits more trial evidence, the incentive of potential relationships to differentiate themselves through contracts falls. As a result, relationships create a smaller set of (simpler) contracts, and fewer relationships enter into a contract. This intuition is incomplete, however. The higher evidence costs that the accuracy-driven enforcer induces are proportional to $\sigma$; that is, the larger is the set of relationships that appear similar to the enforcer on the basis of pretrial evidence, the more evidence the enforcer admits per trial. The consequent high evidence cost induces the enforcer, who pursues efficiency subject always to admitting evidence, to choose an interpretive rule that causes relationships to differentiate themselves more finely in the contracts they write. These complex contracts create smaller partitions of the type space and so reduce the trial costs that a rule always admitting evidence would otherwise cause parties to incur.

Depending on whether the factor driving simple contracts or the factor driving complex differentiated contracts dominates, the optimal number of contracts that the accuracy-driven enforcer induces may be larger or smaller than the optimal number that the welfare-maximizing enforcer induces. The next proposition shows that the number is larger when the evidence cost parameter, $\gamma$, is sufficiently great.

Proposition 2. Assume that $\sigma^{\mathrm{E}}>0$. The following conclusions hold for $\gamma$ sufficiently large. Relative to a welfare-maximizing enforcer, an enforcer who always admits trial evidence but is otherwise welfare maximizing $(a)$ induces fewer relationships to enter into contracts and $(b)$ those that enter into contracts separate themselves with a larger set of more complicated contracts: $\sigma_{0}$ and $K$ are both weakly higher under the accuracy-driven enforcer. Furthermore, $(c)$ regardless of the parameters, welfare is lower under an enforcer who always admits trial evidence.

Remark 4. Trials, especially in the United States, are quite costly; that is, $\gamma$ is large. As a consequence, parts $a$ and $b$ of proposition 2 commonly hold. These, together with part $c$, imply that courts should obey parties' interpretive instructions. Under accuracy maximization, there are too many trials relative to the efficient amount. Interpretive instructions almost invariably truncate the evidentiary base that a court would otherwise use to interpret a contract and so reduce the need for trials. Courts that follow interpretive instructions thus behave more like the ideal enforcer in the 
model. ${ }^{29}$ Therefore, when parties anticipate that a court will follow interpretive instructions, the efficiency with which parties make the requisite trade-offs increases. Proposition 2 also provides a prediction regarding which type of court parties prefer. ${ }^{30}$ If it is optimal in reality to disallow trial evidence for some relationships $\left(\sigma^{\mathrm{E}}>0\right)$, then we expect that parties prefer courts that are more willing to constrain the admission of evidence. There are data consistent with this prediction (see Eisenberg and Miller 2008). ${ }^{31}$

\subsection{The Enforcer's Expertise and Contracting Costs}

Our model permits us to disaggregate the concept of enforcer expertise. The parameter $s$ may take on higher values as the enforcer becomes more expert. Recall that, when a performance is compliant, the signal it sends, $x$, equals the parties' type $t$ with probability $s$. An expert enforcer may be better than a generalist court at inferring type from performance; hence, $s$ is higher for the expert. Similarly, $\gamma$, the cost of using trial evidence, may fall as the enforcer becomes more expert. An expert enforcer may need less evidence to identify type, or be better able to apply evidentiary rules, than would a novice enforcer. Finally, the contracting cost vector $y$ may decrease in enforcer expertise. A particular relationship may need fewer contractual details to individuate itself before an expert enforcer than it would have to include for a lay enforcer.

Regarding the social welfare implications of these variables, we see that for each favorable parameter shift described $(y$ or $\gamma$ lowered, $s$ increased), welfare would weakly rise under the optimal interpretive rule prescribed for the original parameter values (that is, before the shift).

29. Interpretive instructions commonly are relatively context free, for example, "A court shall not use written or oral pre-contractual communications between the parties when interpreting this Agreement." A court could infer from such an interpretive instruction only that the parties are in the large set of types that give interpretive instructions. For further explanation, see note 8 .

30. Parties can choose the interpreting court by including a choice-of-law clause in their contract, which is commonly enforceable regardless of where a transaction is conducted. For example, a contract between Illinois and Kentucky parties will be interpreted under New York law if the parties choose that state's law to govern contracting disputes.

31. In the United States, the California courts' interpretive practices permit parties almost always to introduce trial evidence. In contrast, the New York courts tend to admit trial evidence only when, to use our terminology, other signals of party type are inconclusive. Our analysis shows that full trials are helpful only in a subset of cases. Hence, we speculate that commercial parties prefer their contracts to be interpreted under New York law. Geoffrey Miller and his collaborators show that actual parties prefer New York by a factor of five. 
Thus, by adjusting the interpretive rule to its new optimum, welfare is constant or increases. In particular, parties are more able to communicate their type in the contract when contracting costs decrease, enforcer accuracy increases as an enforcer is better able to infer type from the seller's physical performance ( $s$ is high), and parties supply more context evidence as evidence production cost falls. We summarize this reasoning with Proposition 3.

Proposition 3. Social welfare is weakly decreasing in the vector $y$, increasing in $s$, and decreasing in $\gamma$.

We next consider how these parameters combine to affect social welfare. Contracting costs and enforcer expertise could be complements or substitutes, depending on the nature of enforcer expertise. As complements, when contracting costs fall, parties can write more extensive descriptions. An expert enforcer can combine his ability to evaluate commercial performances with a full description to read the performance signal accurately. As substitutes, the marginal benefit of less costly contracts may decrease in the level of expertise. Parties can send a coarser, and thereby cheaper, contractual signal when the enforcer can identify type using little trial evidence. There is a straightforward relationship among these parameters for large parameter shifts.

Proposition 4. For sufficiently large parameter shifts, expertise measured by $\gamma$ and lower contracting costs (measured by $\boldsymbol{y}$ ) are substitutes, and expertise measured by $s$ and lower contracting costs are complements.

Remark 5. Proposition 4 shows that enforcer expertise operates at two stages of a contracting dispute and invokes three possibly distinct types of enforcer expertise: (1) pretrial, the enforcer can combine his ability to read contracts and his ability to evaluate performance signals with an extensive contract description to recover type with high accuracy, thereby obviating the need for trial evidence, and (2) during trial, the enforcer can combine his ability to evaluate sketchy contracts with his ability to evaluate trial evidence again to determine type with high accuracy, thereby obviating the need for extensive contracts. It is an open question whether an enforcer who is expert at the pretrial litigation stage also is expert at the trial stage. ${ }^{32}$

32. See note 5 . 
Remark 6. The factors that propositions 3 and 4 discuss are choice variables for the state. Thus, the state can reduce contracting costs- $y-$ by requiring commonly used terms to be quoted in standard formats, as is done with the interest rate on consumer loans. The state can increase enforcer expertise- $s$ - by creating specialized courts, such as the commercial part of the New York Supreme Court. The state can reduce trial costs $-\gamma$-by streamlining evidence rules. Proposition 3 implies that each of these strategies would increase welfare gross of implementation costs. Proposition 4 may inform how these strategies are best implemented. For example, certain contracting problems may be complex, litigated frequently, and present in limited contexts. Corporate governance and takeover issues fit this description. States sometimes respond to homogeneity of this type by creating specialized courts, such as the Delaware Court of Chancery and the Israeli corporate court. Proposition 4 suggests that the performance of these courts would be improved were the state also to reduce the relevant sets of contracting costs. Lower contracting costs complement greater enforcer expertise. As another example, many terms in consumer contracts are required to be put in standard forms, so these contracts seem relatively inexpensive to write. Proposition 4 holds that enforcer trial expertise is less valuable as contracting costs fall. This result suggests that recent criticisms that firms require too many consumer contracts to be arbitrated may be well founded.

\section{CONCLUSION}

This paper formally analyzes contract interpretation. We initially show how a welfare-maximizing enforcer induces contracting parties to make socially efficient trade-offs between the gain in better effort incentives that accurate interpretation yields against the costs of contract writing, investment in the deal, and trial costs. We also disaggregate enforcer expertise into three aspects: the ability to extract meaning from words, the ability to infer ex ante intention from tendered performances, and the ability to infer intention from trial evidence. This exercise permits us to show that contract-writing costs and evaluating performances are complements, while contract-writing costs and trial costs are substitutes.

We also develop two significant normative results. First, we show that enforcers who maximize accuracy in interpretation reduce welfare in contrast to enforcers who maximize welfare. The consequences of accuracy maximization include distortions in the extent of contractual specifications, in the fractions of relationships choosing to form con- 
tracts, and in the number of trials, which are more frequent than welfare maximization would imply. Many courts attempt to maximize accuracy. It follows that courts should follow interpretive instructions that parties send when those instructions, as is commonly the case, would have courts reduce the number and scope of trials. Second, we illuminate the state's choice among methods to increase interpretive efficiency. For example, our results permit a more informed choice to be made between specialized and general courts.

Finally, although courts are not optimal enforcers, the cost factors that drive enforcer and party choice are at play in actual settings. Hence, we expect parties to behave, at least roughly, as our model would predict. As noted in Appendix B, it may be relatively convenient to test this view in two dimensions: the complexity of the contracts that actual parties use and their choice of court or arbitrator.

\section{APPENDIX A: ADDITIONAL ANALYSIS AND PROOFS}

\section{Proof of Lemma 1}

This result follows from the seller's first-order conditions and the first and second derivatives of the value functions $v^{\mathrm{E}}$ and $v^{\mathrm{N}}$, when we use the implicit-function theorem and our assumptions on $c$. Q.E.D.

\section{Proposition $1^{\prime}$}

We give here a more detailed version of proposition 1, components of which are useful in the analysis shown in Appendix B. The optimal interpretive rule and the relationships' equilibrium behavior solve the problem of selecting an integer $K$ and numbers $\sigma_{0}, \sigma_{1}, \sigma_{2}, \ldots, \sigma_{K}$ to maximize $\sum_{k=1}^{K}\left[w\left(\sigma_{k}\right)-\sigma_{k} y_{k}\right]$ subject to $\sum_{k=0}^{K} \sigma_{k}=1$. For each $k=1,2$, $\ldots, K, \sigma_{k}$ is the size of the set of relationships that select contract $k$. The solution has the following properties:

a) The derivative $w^{\prime}$ exists at $\sigma_{k}$ for each $k=1,2, \ldots, K$.

b) The difference $w^{\prime}\left(\sigma_{k}\right)-y_{k}$ is constant across $k=1,2, \ldots, K$ and equals zero if $\sigma_{0}>0$.

c) Finally, $w^{\prime}(0)-y_{K+1} \leq w^{\prime}\left(\sigma_{K}\right)-y_{K}$.

Property $b$ states that if the enforcer's interpretive rule partitions potential contracting parties into appropriate sets, there would be no welfare gain from further reshuffling those sets: on balance, any gain in welfare from a switch would be matched by a corresponding contracting cost increase. Property $c$ adds that when the longest (or most complex) 
contract the enforcer's rule induces is contract $K$, welfare would be reduced if a potential relationship wrote contract $K+1$. The practical implication of property $c$ is that no relationship would write this contract.

\section{Proof of Proposition $\mathbf{1}^{\prime}$}

We must show that, if the enforcer partitions relationships by contracts in order to maximize aggregate welfare, then each contracting relationship prefers the contract meant for it. First, notice that it could not be optimal for a relationship to switch from its prescribed contract (or no contract) to another contract, holding fixed the interpretive rule. The enforcer would believe this relationship to have a type in some set $S$ when in fact its type is not in that set. The seller would then have no incentive to invest because the enforcer would believe that her performance was noncompliant. Hence, the contracting relationship would have no value but still would incur a contracting cost. Parties to this relationship would be better off not forming a contract. Second, observe that it could not be optimal for a relationship to switch from its prescribed contract to no contract at all; if it could gain by doing so, then the enforcer would induce the parties not to enter into a contract (which contradicts the assumption that the enforcer maximizes aggregate welfare). This step also uses the fact that decreasing $\sigma$, as would occur when relationships move from contracting to not contracting, has a strictly positive effect on those relationships that remain in the set $S$. These relationships are more likely to have their contracts interpreted accurately.

Regarding the properties of the solution, note that property $a$ follows from the fact that $w$ is the upper envelope of concave functions. The only point where the derivative of $w$ would not be defined is the positive point of intersection between $\sigma v^{\mathrm{E}}(\sigma)$ and $\sigma v^{\mathrm{N}}(\sigma)$, which is $\sigma^{\mathrm{E}}$. At $\sigma^{\mathrm{E}}$, the slope of $w$ from the right is strictly greater than is the slope from the left. If $\sigma_{k}=\sigma^{\mathrm{E}}$ for some $k$, then the enforcer could slightly raise or lower $\sigma_{k}$ and make a corresponding adjustment to some other $\sigma_{l}$, resulting in a strict increase in total welfare (a contradiction). The same logic implies property $b$. Note that if $\sigma_{0}>0$, there must be no way to increase total welfare with a marginal increase in the sizes of any set of relationships choosing the same contract, which means $w^{\prime}\left(\sigma_{k}\right)-y_{k}$ must be zero for all $k=1,2, \ldots, K$. Property $c$ holds that, at the margin, total welfare 
cannot be increased by shifting some relationships from an existing contract to the least-cost unused contract. Q.E.D.

Using proposition 1, we can provide an algorithm for calculating the solution in the two special cases of $\sigma^{\mathrm{E}}=0$ (when it is optimal to always admit context evidence) and $\sigma^{\mathrm{E}} v^{\mathrm{E}}\left(\sigma^{\mathrm{E}}\right)+v^{\mathrm{E}}\left(\sigma^{\mathrm{E}}\right)<y_{1}$ (when it is optimal to always disallow context evidence). We first define, for any $\beta \geq 0$, a sequence $\left\{\mu_{j}^{\beta}\right\}_{1}^{J^{\beta}}$ as follows. ${ }^{33}$ For each positive integer $j$, we look for a number $\mu_{j}^{\beta}$ that solves the equation $w^{\prime}\left(\mu_{j}^{\beta}\right)=y_{j}+\beta$. Because $w$ is strictly concave and differentiable over the relevant region (in both cases considered here), the number $\mu_{j}^{\beta}$ either does not exist (which is the case if and only if $w^{\prime}(0)<y_{j}+\beta$ ) or it uniquely exists. By strict concavity of $w$, that $w^{\prime}(0)=v^{\mathrm{N}}(0)=v^{\mathrm{E}}(0)$, and that $y_{i}$ is unbounded as $j$ becomes large, there exists an integer $J^{\beta}$ such that $\mu_{j}^{\beta}$ is defined if and only if $j \leq J^{\beta}$. Furthermore, $\mu_{j}^{\beta}$ is weakly decreasing in $j$.

If it is the case that $\sum_{j=1}^{J^{0}} \mu_{j}^{0} \leq 1$, then the solution is defined by $K=$ $J^{0}$ and $\sigma_{k}=\mu_{j}^{0}$ for all $k=1,2, \ldots, K$, and in this case we have $\sigma_{0}=1-\sum_{j=1}^{J^{0}} \mu_{j}^{0}$. Otherwise, we choose $\beta$ to maximize $\sum_{j=1}^{J^{\beta}}\left[w\left(\mu_{j}^{\beta}\right)-\right.$ $\left.\mu_{j}^{\beta} y_{j}\right]$ subject to $\sum_{j=1}^{J^{\beta}} \mu_{j}^{\beta}=1$, and this gives the solution.

\section{Proof of Proposition 2}

Recall that the accuracy-driven court uses $\sigma v^{\mathrm{E}}(\sigma)$ in place of $w(\sigma)$. Clearly, $\sigma v^{\mathrm{E}}(\sigma) \leq w(\sigma)$, which proves the welfare claim. Regarding parts $a$ and $b$, note that $w(\sigma)=\sigma v^{\mathrm{N}}(\sigma)$ for $\sigma \leq \sigma^{\mathrm{E}}$, so for such values of $\sigma$ we have to examine the association between using $\sigma v^{\mathrm{N}}(\sigma)$ and $\sigma v^{\mathrm{E}}(\sigma)$ in the solution algorithm. Note that $\sigma v^{\mathrm{N}}(\sigma)$ and $\sigma v^{\mathrm{E}}(\sigma)$ both equal zero at $\sigma=0$. Recall that $q^{\mathrm{E}}$ is constant in $\sigma$, whereas $q^{\mathrm{N}}$ solves $s(1-\sigma)=c^{\prime}\left(q^{\mathrm{N}}\right)$, so we write $q^{\mathrm{N}}(\sigma)$. The derivatives of $\sigma v^{\mathrm{N}}(\sigma)$ and $\sigma v^{\mathrm{E}}(\sigma)$ are, respectively,

$$
v^{\mathrm{N}}(\sigma)+\sigma v^{\mathrm{N}^{\prime}}(\sigma)=q^{\mathrm{N}}(\sigma)-c\left[q^{\mathrm{N}}(\sigma)\right]-s \sigma\left\{1-c^{\prime}\left[q^{\mathrm{N}}(\sigma)\right]\right\} c^{\prime \prime}\left[q^{\mathrm{N}}(\sigma)\right]^{-1}
$$

and

$$
v^{\mathrm{E}}(\sigma)+\sigma v^{\mathrm{E}}(\sigma)=q^{\mathrm{E}}-c\left(q^{\mathrm{E}}\right)-2 \gamma\left(1-s q^{\mathrm{E}}\right) \sigma .
$$

The calculation for the former derivative utilizes the implicit-function theorem to establish that $\partial q^{\mathrm{N}} / \partial \sigma=-s c^{\prime \prime}\left[q^{\mathrm{N}}(\sigma)\right]^{-1}$.

These derivatives are positive and equal at $\sigma=0$, because $v^{\mathrm{N}}(0)=$ $v^{\mathrm{E}}(0)$. Also, both derivatives are strictly decreasing, are continuous, and take negative values for large enough values of $\sigma$. Thus, the inverse

33. In the expressions to follow, where $\beta$ is shown as a superscript, it refers to an index rather than an exponent. 
functions of the derivatives are well defined and continuous on $\left[0, v^{\mathrm{E}}(0)\right]$. Write $g^{\mathrm{N}}(m)=\sigma$ for the inverse of $v^{\mathrm{N}}(\sigma)+\sigma v^{\mathrm{N}}(\sigma)$, and denote by $g^{\mathrm{E}}(m)=\sigma$ the inverse of $v^{\mathrm{N}}(\sigma)+\sigma v^{\mathrm{N}^{\prime}}(\sigma)$. For $\gamma$ sufficiently large, we can guarantee that for every $m \in\left[0, v^{\mathrm{E}}(0)\right)$, it is the case that $g^{\mathrm{E}}(m)<$ $g^{\mathrm{N}}(m)$. This further implies that $\sigma v^{\mathrm{N}}(\sigma)>\sigma v^{\mathrm{E}}(\sigma)$ for all $\sigma \in\left(0, g^{\mathrm{N}}(0)\right)$, so the welfare-maximizing enforcer always disallows evidence.

From the notes following the proof of proposition 1, we know that the optimal interpretive rule of the welfare-maximizing enforcer satisfies $g^{\mathrm{N}}\left(y_{k}+\beta\right)=\sigma_{k}$ for some $\beta \geq 0$ and all $k=1,2, \ldots, K$. Applying the same $K$ and $\beta$ values to the accuracy-driven enforcer yields strictly lower values of $\sigma_{k}$, because $g^{\mathrm{E}}\left(y_{k}+\beta\right)<g^{\mathrm{N}}\left(y_{k}+\beta\right)$. If $\beta>0$ for the welfaremaximizing enforcer, then the accuracy-driven enforcer's optimal interpretation is characterized by a lower value of $\beta$ and, hence, a larger value of $K$, and $\sigma_{0}$ must also be weakly higher because this is zero for the welfare-maximizing enforcer. If $\beta=0$ for the welfare-maximizing enforcer, then the accuracy-driven enforcer's optimal interpretation is characterized by the same value of $\beta$ and, hence, the same value of $K$, and $\sigma_{0}$ must be strictly higher. This proves claims $a$ and $b$. Q.E.D.

It is clear what interpretive rule would be optimally adopted under the constraint that evidence always be allowed. Because $v^{\mathrm{E}}$ is an affine and decreasing function, $\sigma \nu^{\mathrm{E}}(\sigma)$ is quadratic and concave. The interpretive rule thus would partition contracting relationships into equally sized elements, so that $\sigma_{1}=\sigma_{2}=\ldots=\sigma_{K}$.

\section{Proof of Proposition 4}

For a fixed value of $s$, given the constraints in the model, an upper bound on the effort level that can be induced is the value $q^{\mathrm{H}}$ that solves $s=$ $c^{\prime}\left(q^{\mathrm{H}}\right)$. This follows from the seller's first-order conditions in both the evidence and the no-evidence cases; $q^{\mathrm{E}}$ actually achieves this bound and $q^{\mathrm{N}}$ is generally below it. Let $v^{\mathrm{H}} \equiv q^{\mathrm{H}}-c\left(q^{\mathrm{H}}\right)$ denote the joint value for a relationship in this case, gross of contracting costs and without evidence costs. With $s$ fixed, $v^{\mathrm{H}}$ is a type's highest possible joint value.

Respecting part $a$ of the proposition, let us start from any given values of the other parameters. As $\gamma$ approaches zero, the seller's effort comes arbitrarily close to $q^{\mathrm{H}}$, so the relationship's joint value comes arbitrarily close to $v^{\mathrm{H}}$ regardless of the parameter $y$. This result also obtains if contracting cost $y$ converges to zero, so that relationships could distinguish themselves finely by their contract selection; that is, as $y$ approaches the zero vector, the seller's effort comes arbitrarily close to $q^{\mathrm{H}}$ 
and the relationship's joint value comes arbitrarily close to $v^{\mathrm{H}}$ regardless of the parameter $\gamma$. Thus, low values of $\gamma$ and $y$ are substitutes in the large.

Respecting part $b$, we see that an almost efficient level of effort $q^{*}$ can be induced only if $s$ is high and at least one of the other shifts just discussed occurs. Recall that $x$ is the signal that the seller's performance generates. If the seller complied, then $x=t$ with probability $s$, and $x$ is uninformative with probability $1-s$ (that is, $x$ is uniformly distributed over $[0,1])$. If the seller breached, $x$ is similarly uninformative. Hence, a compliant performance under a low $s$ is equivalent, in the enforcer's view, to a breach. It follows that a seller cannot be given good incentives unless $s$ is high. But if $s$ is close to one, then sufficiently lowering the vector $y$ will motivate the seller to select an effort level that is arbitrarily close to $q^{*}$. Hence, expertise measured by $s$ and improved language are complements for large enough shifts. Q.E.D.

\section{APPENDIX B: AN EXTENSION tO THE OPTIMAL USE OF MULTIPLE ENFORCERS}

Here we briefly discusses how the optimal interpretive rule induces choices between different enforcers: a court and an arbitrator. The arbitrator is assumed to have greater expertise in evaluating performances because it is more common for arbitrators to have pertinent industry knowledge. Formally, we let $s^{\mathrm{C}}$ and $s^{\mathrm{A}}$ denote the levels of expertise of the arbitrator and the court, with $s^{\mathrm{A}}>s^{\mathrm{C}}$. An important assumption is that, holding contract type constant, to use an arbitrator imposes an additional contracting cost of $\alpha \geq 0$ for each relationship served. All other parameters remain as before.

We motivate the addition of the contracting cost $\alpha$ as follows: the state provides detailed procedures that govern the pretrial and trial stages of litigation in courts. These procedures are long-standing and are glossed by many precedents. Parties can opt into rule systems that govern arbitration-the rules of the American Arbitration Association, for example-but those rules are much less detailed and less predictable in application than the state's procedural rules. ${ }^{34}$ Parties that choose arbitration thus have to create some procedures of their own.

34. For example, an arbitration panel's interpretation of an American Arbitration Association rule often is not publicly reported. Hence, precedents seldom inform the application of these rules. In contrast, there is a set of reporters-the Federal Rules Decisions-that report interpretations of the Federal Rules of Civil Procedure. 
In this setting, an interpretive rule would determine the enforcer to which parties using particular contracts are directed. The interpretive rule also would specify when the buyer must pay and when trial evidence is allowed, as before. Proposition 1 therefore continues to characterize the optimal interpretive rule, with one modification: the welfare function $w$ is now defined by

$$
w(\sigma) \equiv \sigma \max \left\{v^{\mathrm{CE}}(\sigma), v^{\mathrm{CN}}(\sigma), v^{\mathrm{AE}}(\sigma)-\alpha, v^{\mathrm{AN}}(\sigma)-\alpha\right\},
$$

where $v^{\mathrm{CE}}$ and $v^{\mathrm{CN}}$ denote the values of a relationship under court enforcement with and without trial evidence allowed, respectively, and $v^{\mathrm{AE}}$ and $v^{\mathrm{AN}}$ denote the values under arbitration. This expression represents that, under the optimal rule, a set of relationships of size $\sigma$-those that use the same contract-can be directed to either the court or the arbitrator, and context evidence may be either allowed or disallowed. ${ }^{35}$

The modified welfare expression suggests why two enforcement systems can coexist. For sets of relationships that use different contracts, some may benefit more from arbitrator expertise and optimally would be directed to the arbitrator, while others optimally would be directed to the court. To make this precise, we investigate how the marginal benefit of expertise depends on the size $\sigma$ of a set of relationships that choose the same contract. We proceed by providing two lemmas that help sort out (1) the association between $\sigma$ and whether relationships are optimally sent to arbitration or to court and (2) the association between $\sigma$ and the slope of the welfare function, $w$. To produce the first lemma, for convenience we limit attention to a special case in which the cost function for the seller's investment in quality is $c(q)=q^{2} / 2$.

\section{Lemma 2}

Assume $c(q)=q^{2} / 2$ and take as given an arbitration cost $\alpha$ and expertise levels $s^{\mathrm{C}}$ and $s^{\mathrm{A}}$ satisfying $s^{\mathrm{A}}>s^{\mathrm{C}}$. There are numbers $z^{0}$ and $z^{1}$ satisfying $0 \leq z^{0} \leq z^{1} \leq 1$, such that

i) $v^{\mathrm{AN}}(\sigma)-\alpha>v^{\mathrm{CN}}(\sigma)$ for all $\sigma \in\left(z^{0}, z^{1}\right)$, and

ii) $v^{\mathrm{AN}}(\sigma)-\alpha<v^{\mathrm{CN}}(\sigma)$ for all $\sigma \in\left(0, z^{0}\right)$ and for all $\sigma \in\left(z^{1}, 1\right)$.

35. Further variations of this extension are also possible; they amount to variations in the definition of $w$. For example, to represent the case in which the court maximizes accuracy in interpretation (and thus always admits context evidence), we remove $v^{\mathrm{CN}}$ - the value of relationships in court when the court excludes context evidence-from the definition of $w$. 
Furthermore, if $\alpha$ is sufficiently small, then $z^{0}=0$. Also, $z^{1}-z^{0}$ is decreasing in $\alpha$.

\section{Proof of Lemma 2}

Note that with $c(q)=q^{2} / 2$, we get $q^{\mathrm{N}}=s(1-\sigma)$. Substituting this into the expression for $v^{\mathrm{N}}$ yields

$$
v^{\mathrm{N}}(\sigma)=s(1-\sigma)[2-s(1-\sigma)] / 2 .
$$

We have $\partial^{2} v^{\mathrm{N}} / \partial^{2} \sigma \partial s=-2 s<0$. Thus, as $s$ increases, $v^{\mathrm{N}}$ becomes more concave and the value of $v^{\mathrm{N}}(0)$ rises. An implication is that if $v^{\mathrm{AN}}(\sigma)-$ $\alpha=v^{\mathrm{CN}}(\sigma)$ for some value of $\sigma$ for which $v^{\mathrm{AN}^{\prime}}(\sigma)<v^{\mathrm{CN}^{\prime}}(\sigma)$, then $v^{\mathrm{AN}}\left(\sigma^{\prime}\right)-\alpha<v^{\mathrm{CN}}\left(\sigma^{\prime}\right)$ for all $\sigma^{\prime}>\sigma$. We conclude that $v^{\mathrm{AN}}(\sigma)-\alpha$ and $v^{\mathrm{CN}}(\sigma)$ intersect at most twice, with $v^{\mathrm{AN}}(\sigma)-\alpha>v^{\mathrm{CN}}(\sigma)$ in the interior region. This proves claims $\mathrm{i}$ and ii of the lemma. Note also that $\partial v^{\mathrm{N}} / \partial s=(1-\sigma)[1-s(1-\sigma)]>0$, so $v^{\mathrm{AN}}(0)>v^{\mathrm{CN}}(0)$. This implies that when $\alpha$ is small, $z^{0}=0$. The last statement of the lemma follows from the concavity of $v^{\mathrm{AN}}(\sigma)$. Q.E.D.

Part i states that when both enforcers exclude context evidence, then, holding contract type constant, the value of relationships is greater in arbitration when relatively few relationships use this contract, unless the cost of specifying arbitration $(\alpha)$ is large. Part ii holds that this result reverses when the number of relationships using a particular contract grows. ${ }^{36}$ Regarding the intuition, the association between relationship type and performance under a contract becomes attenuated as more types use the same contract. The arbitrator's expertise consists in inferring type from performance. Hence, as this ability becomes less valuable, parties do better going to court and saving the cost $\alpha$ of writing arbitration specifications. This result also holds when comparing $v^{\mathrm{AN}}(\sigma)$ and $v^{\mathrm{CE}}(\sigma)$ : that is, when holding $\sigma$ constant, an accuracy-driven court would admit evidence that an arbitrator would disallow. When the contracting cost is relatively low and trials are relatively costly, it is optimal to send type sets with a small value of $\sigma$ to the arbitrator and sets with a large value of $\sigma$ to the court.

The second lemma concerns the association between $\sigma$ and the slope of $w$. Since $w$ is not strictly concave, there may be multiple points with the same slope, so we look at the set of points at which the slope is some value $m,\left\{\sigma \mid w^{\prime}(\sigma)=m\right\}$.

36. This comparison between $v^{\mathrm{AN}}(\sigma)$ and $v^{\mathrm{CN}}(\sigma)$ is relevant when $\gamma$ is relatively large so that $\sigma^{\mathrm{E}}>0$. 


\section{Lemma 3}

The set $\left\{\sigma \mid w^{\prime}(\sigma)=m\right\}$ is decreasing in $m$ in the sense that as $m$ increases, the end points of the set $\left\{\sigma \mid w^{\prime}(\sigma)=m\right\}$ decrease.

\section{Proof of Lemma 3}

This lemma follows from the fact that $w$ is the upper envelope of concave functions $\sigma v^{\mathrm{CN}}(\sigma), \sigma v^{\mathrm{CE}}(\sigma), \sigma v^{\mathrm{AN}}(\sigma)-\sigma \alpha$, and $\sigma v^{\mathrm{AE}}(\sigma)-\sigma \alpha$. Note also that the derivative of $w$ is maximized at $\sigma=0$. Q.E.D.

This lemma holds that, generally speaking, when $\sigma$ is small-that is, relatively few types use a similar contract-then welfare is increasing relatively sharply. Lemma 3 is independent of the specific functional form that $c(q)$ may take.

Lemmas 2 and 3, along with our earlier results, give some predictions that one could, in principle, test. To derive the first prediction, recall that the contract space is ordered by cost, so that for any two contracts $k>j$, the cost $y_{k}$ of contract $k$ is weakly larger than is the cost $y_{j}$ of contract $j$. This implies, practically, that contract $k$ is longer and more complicated than is contract $j$. One can measure contract length by the number of words. Property $b$ of proposition 1 holds that longer contracts are associated with larger marginal values of the welfare function, $w$. That is, for contracts $k$ and $j$ with $y_{k}>y_{j}$ (so contract $k$ has more words), the optimal interpretive rule creates partitions $\sigma_{k}$ and $\sigma_{j}$ satisfying $w^{\prime}\left(\sigma_{k}\right)>w^{\prime}\left(\sigma_{j}\right)$. Lemma 3 then implies that, up to an equivalence set, $\sigma_{k}$ is smaller than $\sigma_{j}$. We thus predict that, across all contracts written in the population of relationships, there is an inverse relationship between contract length (measured by the number of words) and the number of relationships choosing a specific contract of this length. ${ }^{37}$

For a second prediction, suppose that $\alpha$ is small and $\gamma$ is relatively large, so that the optimal interpretive rule directs type sets with small values of $\sigma$ to the arbitrator and sets with large values of $\sigma$ to the court. Because $\sigma$ is inversely related to contract length, we expect longer con-

37. The prediction refers to the frequency with which relationships use a specific contract. For a given number of words, $\lambda$, there are a number of potential contracts with exactly $\lambda$ words. The number of such contracts is increasing in $\lambda$. Thus, if we found that the number of relationships choosing contracts with $\lambda$ words is itself increasing in $\lambda$, the finding would not contradict our prediction. The predicted association would be confirmed, however, if data show an inverse correlation between $\lambda$ and the number of relationships choosing contracts with $\lambda$ words. 
tracts to specify arbitration more frequently. ${ }^{38}$ A contributing factor to this prediction is that parties who choose arbitration sometimes must specify litigation procedures; doing this makes contracts longer. A possible countervailing factor is that, as shown in lemma 2, if $\alpha$ or $\gamma$ is moderate, litigation in court may be optimal for some sets of relationships when $\sigma$ is small (that is, a few relationships write very long contracts). Thus, we predict a positive relationship between contract length and the choice of arbitration, except perhaps for the longest contracts.

Our conclusion about the benefit of multiple enforcers is consistent with the existence, in almost every industry studied, of a positive fraction of contracts that contain arbitration clauses (for example, Eisenberg and Miller 2007; Drahozal and Ware 2010). The use of arbitrators and variations in interpretive rules across enforcement systems and jurisdictions allows parties more precisely to convey context information, so each contractual relationship has an enhanced probability of receiving an interpretive style tailored to its type.

\section{REFERENCES}

Anderlini, Luca, and Leonardo Felli. 1999. Incomplete Contracts and Complexity Costs. Theory and Decision 46:23-50.

$\rightarrow$ Battigalli, Pierpaolo, and Giovanni Maggi. 2002. Rigidity, Discretion, and the Costs of Writing Contracts. American Economic Review 92:798-817.

$\rightarrow$ Drahozal, Christopher R., and Keith N. Hylton. 2003. The Economics of Litigation and Arbitration: An Application to Franchise Contracts. Journal of Legal Studies 32:549-84.

Drahozal, Christopher R., and Stephen J. Ware. 2010. Why Do Businesses Use (or Not Use) Arbitration Clauses? Ohio State Journal on Dispute Resolution 25:433-76.

$\rightarrow$ Dye, Ronald A. 1985. Costly Contract Contingencies. International Economic Review 26:233-50.

Eisenberg, Theodore, and Geoffrey P. Miller. 2007. Flight from Arbitration: An Empirical Study of Ex Ante Arbitration Clauses in the Contracts of Publicly Held Companies. DePaul Law Review 56:335-74.

2008. The Flight to New York: An Empirical Study of Choice of Law

38. We are presuming here that, to be directed to arbitration, the parties have to specify arbitration in their contract. Our model is silent on the actual words used in the contract. Note that a positive correlation between a measure of complexity and the probability that parties choose arbitration is found by Drahozal and Hylton (2003) and Drahozal and Ware (2010). 
and Choice of Forum Clauses in Publicly-Held Companies' Contracts. Working paper. New York University Center for Law and Economics, New York.

$\rightarrow$ Kvaloy, Ola, and Trond E. Olsen. 2009. Endogenous Verifiability and Relational Contracting. American Economic Review 99:2193-2208.

$\rightarrow$ Listokin, Yair. 2010. Bayesian Contractual Interpretation. Journal of Legal Studies 39:359-74.

$\rightarrow$ Maggi, Giovanni, and Robert Staiger. 2011. The Role of Dispute Settlement Procedures in International Trade Agreements. Quarterly Journal of Economics 126:475-515.

Posner, Richard. 2004. The Law and Economics of Contract Interpretation. Texas Law Review 83:1581-1614.

$\rightarrow$ Schwartz, Alan, and Robert E. Scott. 2003. Contract Theory and the Limits of Contract Law. Yale Law Journal 113:541-619.

—. 2010. Contract Interpretation Redux. Yale Law Journal 119:926-64.

$\rightarrow$ Schwartz, Alan, and Joel Watson. 2004. The Law and Economics of Costly Contracting. Journal of Law, Economics, and Organization 20:2-31.

- 2012. Conceptualizing Contractual Interpretation. Research Paper No. 447. Yale University, John M. Olin Center for Studies in Law, Economics, and Public Policy, New Haven, Conn.

$\rightarrow$ Shavell, Steven. 2006. On the Writing and the Interpretation of Contracts. Journal of Law, Economics, and Organization 22:289-314.

Zhao, Xiaojian. 2010. Economics of Contract Interpretation. Pp. 61-73 in Research in Law and Economics, edited by Richard O. Zerbe and John B. Kirkwood. Bingley: Emerald Group. 